
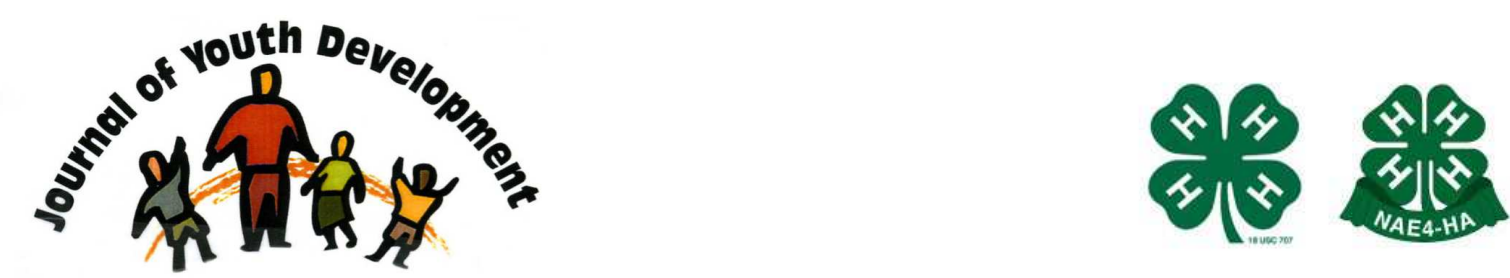

Bridging Research \& Practice

\title{
Youth in Community Decision-Making: A Study of Youth-Adult Partnerships
}

\author{
Shelley Murdock \\ 4-H Youth Development \\ University of California Cooperative Extension \\ Pleasant Hill, CA \\ swmurdock@ucdavis.edu \\ Carole Paterson \\ 4-H Youth Development \\ University of California Cooperative Extension \\ Mary Claire L. Gatmaitan \\ Graduate Student Intern \\ University of California Cooperative Extension
}




\title{
JOURNAL OF YOUTH DEVELOPMENT \\ bridging research and practice

\section{Youth in Community Decision-Making: A Study of Youth-Adult Partnerships}

\author{
Shelley Murdock, Carole Paterson and Mary Claire L. Gatmaitan \\ University of California Cooperative Extension
}

\begin{abstract}
Involving youth in community and organizational decisionmaking is widely believed to lead to stronger communities. A promising strategy to foster decision-making is youth-adult partnerships in which youth and adults work collaboratively, sharing their strengths, collective knowledge, and decision-making power. A qualitative study of eight youth organizations showed that those organizations employing youth-adult partnership strategies were most effective in increasing youth's contributions to their communities. This article explores the elements of youth-adult partnership that were evident among successful organizations including: mutual respect, meaningful roles for youth, unique contributions of adults and youth, and shared decision-making and implications for youth development programs.
\end{abstract}

\section{Introduction}

During our agricultural era, youth learned about adult life and their roles in communities by working side-by-side with adults at home and through apprenticeships. As our society shifted to an industrial base, youth and adults spent significantly less time together. Today, young people spend most of their time in age-segregated schools and after-school leisure activities involving relatively few adults (Zeldin, McDaniel, Topitzes, \& Calvert, 2000).

As age-segregation evolved many adults began to perceive youth negatively. In the 1960's and 70's a variety of deterrence programs, followed by prevention programs, were initiated to address adults' increasingly negative perceptions of youth. Although many adults still believe youth are incapable, aggressive, and lazy (Males, 1999), current program emphasis has shifted from correcting potential poor or "at-risk" behavior to positive youth development. The positive youth development paradigm recognizes that most adolescents are "self-directed learners and 
critical thinkers who are able to make positive contributions to society and the environment" (Zeldin, et al., 2000, p.6).

Nonetheless, most programs are still adult planned and led with youth having relatively little decision-making power. These programs are sometimes counteracted with youth-led programs in which youth, without skills or coaching, are "turned loose" to run their own programs. This practice can be equally ineffective and/or disempowering (Norman, 2001). Adults' perceptions of youth affect their beliefs about whether young people can or cannot make meaningful contributions. A study in Wisconsin and Washington found that there are more adults who have little or no confidence in youth's decision-making capabilities than adults who believe that youth are capable decision-makers (Zeldin, et al., 2000). These attitudes influence the extent to which adults are willing to involve young people as significant partners (Norman, 2001).

William Lofquist (1990) described three categories of adult perceptions that affect adult and youth interactions:

- Youth as Objects: Adults know what is best for young people and control situations in which they allow them to be involved.

- Youth as Recipients: Adults allow young people to take part in decision-making because they think the experience will be "good for them."

- Youth as Resources. Adults respect young people as having something significant to offer and youth are encouraged to become involved.

Youth in governance is defined by National 4-H Council as "the authentic and meaningful engagement of young people in programs, organizations and communities where they have or share voice, influence and decision-making authority" (2005). It is widely believed to lead to innovative solutions, stronger communities, and an increased sense of self-worth among participating young people (Zeldin, et al., 2000). Emerging research suggests that organizations using a youth in governance approach achieve better youth development outcomes than organizations focused solely on youth development (Gambone, et al., 2004; MacNeil, 2005).

Youth-adult partnerships, in which adults and youth each contribute their unique strengths to the relationship, is a promising methodology for increasing youth in governance thus fostering positive youth development (Fiscus, 2003). Youth involved in positive, meaningful, respectful relationships with adults have been shown to improve skills and competencies in areas such as communication and leadership while decreasing participation in risky behaviors. When partnering with youth, adults also build skills while strengthening the organizations to which they belong (Innovation Center for Community and Youth Development, 2003).

Youth-adult partnerships require that adults share power while providing youth with the tools and training to succeed as full partners in the decision making process. Shared decision-making is identified as the most salient element in fully realizing authentic youth voice and meaningful community involvement (Fiscus, 2003). Genuine shared decisions are those that "clearly reflect dialogue and discussion with youth" (Goggin, Powers, \& Spano, 2002, p. 26).

In our work with community agencies, we often found that even those agencies with a stated mission of involving youth in decision-making sometimes fell short of their goals while others were successful. We were interested in finding out what key factors community organizations 
successfully used to engage young people and foster voice in their organizations and the larger community.

In our study, we found that programs in which youth had high levels of decision-making and voice were neither adult-led nor youth-led, but those that engaged youth and adults in partnerships. This paper describes how youth development practitioners and youth operationalize youth-adult partnership. Our study is grounded in conversations with diverse youth who are engaged and have voice in their communities and the adults who partner with them.

\section{Methods}

The research team, comprised of three experienced academic researchers and one young, multi-lingual graduate student intern, examined eight organizations in the San Francisco Bay Area. All of the organizations had stated missions of promoting youth decision-making and community involvement. Reputational sampling (Patton, 2002) was used to identify exemplary organizations that were known through professional networks and word-of-mouth reputation to use promising practices. We interviewed staff who conduct programs and young people who participate in these programs to identify factors that affect organizations' ability to foster youth engagement and voice.

The community organizations that participated in this study included five nonprofit organizations and three government sponsored programs, two of which were youth commissions and another program devoted to employment for teenagers. The contexts of these organizations included:

- local government

- drug and alcohol abuse prevention

- leadership development

- youth development

- empowerment of students of color and of youth who are gay, lesbian, bisexual, or transgender.

Twelve program staff members from the eight organizations completed a brief written demographic survey and were interviewed individually or in pairs by the senior research team members. The survey asked for information on ethnicity, years in the program, and educational level. The graduate student interviewed forty program participants ranging in age from 13 to 19 years old. The youth completed a brief demographic survey that asked their age, ethnicity, and level of program involvement. They were interviewed in groups of four to eight from the same organization. The youth sample was comprised of $60 \%$ ethnic minority youth including some who were very recent immigrants.

Interviews for both adults and youth were about two hours in length, audio taped and transcribed verbatim by professional transcribers. Interview protocols were used with both groups. They consisted of questions that were designed to elicit identification of effective strategies for youth voice and participation. For example, youth were asked about their roles in the organization, preparation for their roles, and their relationship with peers and with the adults. Interview protocols were piloted and interview questions rearranged to facilitate a smooth conversational flow. All interview protocols and the demographic surveys were 
reviewed and approved by the IRBPHS at the University of California at Davis. Parents signed participation consent forms for their minor children.

Within 24 hours of each interview, researchers completed an interview summary describing interview locale, unusual circumstances, and significant aspects of the interview. Transcribed interviews were analyzed using qualitative data analysis methods (LeCompte, \& Schensul, 1999). Research team members read all of the interview transcripts but categorized and coded interviews individually to expedite the process. The research team met regularly during coding to review the process and discuss emerging categories and themes. A summary of recurring ideas as well as factors that were particularly innovative and unique based on the research literature and knowledge of the field are presented. The quotes we included were selected to represent a general trend in the participants' responses as well as for their richness and range.

\section{Findings}

Within our sample of eight organizations, we found a wide range of programs with widely varying success in promoting youth engagement and voice. We found that some programs manifested more of the successful practices which are identified in the literature. These programs generally:

1) Provide young people with meaningful and authentic experiences.

2) Infuse or involve youth in innumerable aspects of the program and the organization.

3) Employ adults with a high level of education or knowledge about young people and a demonstrated willingness to share power with them.

4) Have adequate resources and funding to accomplish their stated goals.

5) Regarded favorably by youth. That is, youth expressed positive opinions and attitudes about the programs, saying that they contribute in meaningful ways and that their voices are heard.

6) Facilitate youth and adult partnerships in which both parties contributed strengths and resources and learn from each other for mutually beneficial results.

We chose to focus this paper on youth-adult partnership strategies because the three organizations that were most successful in fostering youth voice and decision-making typically employed youth-adult partnership strategies. Others exhibited some characteristics of youthadult partnerships and often possessed other strengths such as providing needed support and resources for ethnic minority or marginalized youth. Those agencies that seldom involved youth in authentic roles at the local, organizational or programmatic level appeared to employ few youth-adult partnerships strategies.

According to current research, strong youth-adult partnerships share characteristics of mutual respect; authentic roles for youth and adults (Zeldin, et al., 2000); mutuality in teaching, learning, and action (Camino, 2000b); and an articulated process for shared decision-making. Using the voices of the practitioners and young people interviewed, we present examples of how successful agencies operationalize these strategies in the following sections. 


\section{Mutual Respect}

Respect among program youth and adults was readily evident in those programs employing youth-adult partnership strategies. The youth valued respectful interactions with their peers, stating that this respect resulted in a family feeling and better group dynamics. Adults also respected one another. For example, a supervisor demonstrated respect by honoring staff members' personal time and family commitments.

Of these, however, a concerted effort to foster respect between youth and adults was a distinguishing characteristic of youth-adult partnerships. This staff person worked for a gaylesbian empowerment program which was not always well-received in all communities:

To be an adult ally, to really support youth it's not just saying it verbally but it's acting upon that commitment to really support the youth in what they want to see changed. And sometimes it's putting your neck out there to really support them.

When asked about the elusive quality of "good chemistry" between youth and adults, staff responses indicated that respect was the core of chemistry:

I think any adult, however, old or young, can have chemistry with youth, a positive rapport. I think it's the approach that you take and the respect you have for them and their culture and their environment and not to feel like you've got to come in and push the way you were raised onto the way they're being raised, because it's totally different.

Listening for understanding, honest communication, and a willingness to solicit and consider youth's ideas and requests, even ideas that staff recognized as potential liabilities, were reported as important elements of respect by youth and adults:

A lot of times its face-to-face conversations to be able to say, you know what, this sounds like a really cool idea, but it is probably not going to be possible at this time and here are the reasons why. It's not to shoot down your idea. But I want to tell you this might put us in jeopardy or this might make it hard for us to do this program again. So, is there another way for us to not lose the energy of those ideas, but to be able to think about how we still take that idea and maybe tweak it so that it can work in our organization?

Although some youth complained that adults sometimes "helped too much" by providing suggestions and guidance youth considered unnecessary, youth in strong youth-adult partnerships appreciated and respected the adults' contributions. These remarks from two city government youth commissioners are typical of young people's respect for the adult partners with whom they worked:

The staff we have now, they're the best. They support us with everything. They'll help us, they give suggestions, they work so hard so that we look good and do well. I'd say actually they make sure that we do our job well, they help us with almost anything we could ask them to help us with.

If I ever have questions, I don't feel intimidated to ask them, and I'm sure they'd answer. They might even go beyond that and say, "Oh, you can meet with me also on this day and we can talk about it," things like that.

Lack of respect reported by youth often took the form of adults not trusting the youth to assume leadership roles or adults soliciting ideas from the youth then ignoring these ideas. For 
example, an adult leader in one organization stated, "I think the kids have a lot of input. I can give Mary an idea and she'll take it to the teacher . .." Youth in this same organization also reported:

You put in an opinion and a person says "Oh, yeah, great idea. I'll talk to someone about it" and you ask them about it later and it's like they don't even remember it. It's happening most of the time, so why voice your opinion if you're not going to get heard.

\section{Meaningful Roles and Community Contributions}

A second youth-adult strategy exhibited by strong programs was opportunities for youth to assume meaningful roles and make significant contributions to their communities. Youth acknowledged that adults took them more seriously when they presented ideas on significant community issues, such as multi-cultural understanding or gun safety, than when they presented ideas on more typical youth-related issues such as the creation of skate parks. When asked whether or not youth in his program made a difference, this young person stated: I think any time youth come together and especially from different races or stuff that we do make a difference, because people are excited to see youth in the community who are doing something positive, because that's not what they usually see, so I think we do.

Staff reported similar contributions and results:

They're very respected in this community and they're very engaged and people want to know what they think. And just to be in a position where an entire room of people or TV cameras and reporters ask you what you think. And they listen and they wait for you to say it. For someone who's 14 years old to feel that. Even when they are experts on the issue, (they) have never been treated as such. It's an immense feeling of empowerment and we really see that change a lot.

Commissioners are getting more savvy, they're having stronger relationships with the government and they are getting more and more respected. Their influence on the budget is growing more and more.

Staff of programs based on youth-adult partnerships used many strategies to motivate youth and to increase opportunities for youth to contribute to their communities:

I think we are learning that we have to find new ways to motivate them to develop their consciences. You have to use methods around their lifestyle, hip hop, their own community, their own cultural background as a means to motivate them and develop their consciousness and organize other students.

One leadership program motivated and increased the meaningful involvement of all youth by eliminating a hierarchical structure, including officers. Each week the youth assumed a new and different role which helped them learn and practice new skills. Several youth mentioned that they appreciated this structure:

Each person gets a chance to actually take some responsibilities and that's good because we can learn different skills. Like as a facilitator you learn how to facilitate a meeting . . . and take notes as the secretary. . . it's very good and it makes us feel like we are not left out. 
Meaningful roles for youth were not evident in all the programs. For example, one governmental organization claimed to connect youth to their communities but had no stated roles or expectations for program youth. An older adult staffer said, "We even give them a mentor if they need it, and hopefully these young people stay out of trouble during the danger hours, which are from 3:00 to 6:00 every day." A second staff person, with higher expectations for youth complained, "and then at the event that they help plan, the youth are just there setting up tables or cleaning up garbage."

\section{Unique Contributions and Mutuality}

Youth-adult partnerships are relationships between youth and adults where there is mutuality in teaching, learning and action (Zeldin, McDaniel, Topitzes, \& Lorens, 2001). Youth-adult partnerships capitalize on the unique contributions that adults and youth each bring to the partnership.

Adults in strong youth-adult partnerships contribute training and support to help youth increase their knowledge, skills and experience. They taught, and sometimes learned with the youth, a wide range of skills such as networking, accessing public officials, facilitating meetings, convening and moderating forums, public speaking, research methods, teaching, and writing press releases. Additionally, they actively sought opportunities for youth to use these skills in authentic community situations.

Adults in partnerships also connected youth with other adults in the community who supported the youth's work. For example, one adult staff person recruited a school board member known for open-mindedness to help the youth initiate an AIDS/HIV campaign in his school district. The board member taught the youth how to get "the best people" to meetings and how to enlist the support of other board members. When the board voted on the youth's proposed resolution, it passed.

Enthusiasm and creativity were typically the most cited youth contributions in all eight programs we studied. Adults reported that youth energized adults and provided program impetus. An adult partner with a youth commission returned from an 11- day experience working with youth and described why she chose this line of work: "I came back from that, I was like, I think I want to work with youth, they're really inspiring, you know? (They're) always alive."

In strong partnership programs adults recognized and valued that the youth are highly effective in knowing the needs, planning appropriate programs to address identified needs, and reaching diverse groups of their peers with messages about racial tolerance, safe sex, local policies affecting youth, and other social issues.

Mutuality, that is learning together, honest communication, and sharing tasks, is believed to lead to synergy in which there is greater productivity, innovation, and commitment than would occur in youth-only or adult-only projects (Zeldin, et al., 2000). An example of mutuality in our study was when we asked a staff person how she knew about the intricacies of the city budget and she responded, "I don't. I'm constantly learning, we all are." She enthusiastically enjoyed learning with youth and derived great satisfaction from her work. She went on to describe a typical day where she developed a youth training workshop on the city budget process, researched legislation on consent and confidentiality issues for high schools, and attend a hearing where six youth commissioners testified. She described the hearing and her day: 
And then I got to go to a meeting on how to have a safe city-wide youth event in the city (at which) young people came together and try to create their own community security teams and things that don't involve the police. So I was like, what a cool day. It was a great day! Wow, this is a great job! It was great.

Although evidence of mutuality was sometimes elusive in otherwise strong programs, it was notably absent in weaker programs. For example, in these programs some training was open only to adults, adults held meetings during school hours, and adults often filtered information they obtained at meetings attended.

\section{Shared Decision-Making}

At the core of youth-adult partnerships is shared decision-making. Adults who serve as partners believe that youth should make many decisions, especially decisions about governing their own program. For example, an adult partner in a leadership program shared her knowledge of various meeting processes, including parliamentary procedure, facilitation, and others. The youth then discussed the strengths and weaknesses of each process, chose one, and used it to plan and run all their meetings. The staff of two other successful programs shared this selfgovernance philosophy:

They need to feel like they ultimately make the decisions for this group ... an end to the means type of thing. The end (product) of the Youth Commission is to further youth voice in city government. And so if the Commission itself doesn't function that way, then it's hypocrisy. We believe that. We really, really believe that.

They decide on membership policies, they contract for rooms, they decide on short and long-term goals, they facilitate the meetings, they do self-evaluations annually and biannually. . . There's no aspect they don't lead.

We found many examples of shared decision-making in those programs in which the adults viewed the youth as partners, capable of making thoughtful, deliberative decisions about their own governance as well as broader, community-wide decisions:

We never choose the way they're going to go about these projects. . . there's that respect, "Look you guys are in charge here, you know, you're making the decisions about what you work on and how you do this."

And we really believe that youth have great ideas and great solutions to the negative conditions in their schools and communities.

Youth appreciated programs in which they had decision-making responsibilities. For example, one youth said, "I definitely think that my voice is being heard here and I'm making an impact on the decisions -- decisions and events that we choose and plan to do."

Another youth compared the program we studied, in which youth were denied decisionmaking, with another program in which she participated:

I'm in (the) leadership yearbook program at school, and we vote on everything, and we talk about lots of stuff and why we should do things and why we shouldn't. In the long run, I think it does matter and it is a little time consuming, but I think it really . . . I think it matters to me. 
The decision-making role of adults in successful partnerships often took the form of facilitator who helped the youth gather information, reflect on issues, and make decisions:

We have an adult facilitator and she sits in with us in every meeting. She doesn't play a part of "head master" but she's basically another youth in there but sometimes if things are getting out of hand or need to be talked about then she'll step in and say we need to work on this. But other than that it's pretty much youth done and we don't have a ring master.

Adults in partnerships also implemented many strategies to increase youth's community decision-making opportunities and to break down barriers. Examples included advocating for accessible meeting locations and times, asking school principals to accept the youth's participation on boards as independent study, enlisting adult allies in the community, explaining jargon to the youth, and promoting a positive image of youth within the organization and the community.

\section{Discussion}

Although three of the eight organizations demonstrated very strong youth-adult partnerships, this was fewer than was anticipated considering the highly-regarded reputation of the agencies we studied. This was especially noticeable in the area of decision-making. In some programs we found that the adults made more decisions than the youth. These youth were most often excluded from broad, organizational decisions and in some agencies, from even making decisions about the governance of their own programs.

We found a number of factors contributing to these variations that were consistent with those cited in the literature (e.g. Camino, 2000a; Stoneman, 2002; Zeldin, et al., 2000) including:

- limited resources

- restrictive organizational structures

- lack of knowledge about youth-adult partnerships

- lack of knowledge about developmental characteristics of youth

- and most significantly, the adults' perception of youth.

Interviews with adults indicated that their perceptions of youth generally fell into those categories described by Lofquist (1990): youth as objects, youth as recipients, or youth as resources. The interviews also indicated that these perceptions related to the level of decisionmaking they shared with the youth. For example, in one governmental agency with a stated mission of involving youth in community decision-making, the adult staff planned the agendas and ran all of the youth meetings, indicating that the adults viewed the youth as objects. One staff member stated, "The issues that the Council deals in are complicated and they're really not things that the youth can contribute a lot to." Lack of decision-making was found in other programs where the adults perceived youth as objects or as recipients.

Also consistent with the literature, some adults' seemed to believe that their job was to educate, direct, and discipline youth as opposed to fostering youth's decision-making skills (Stoneman, 2002) and some adults seemed reluctant to pass the torch that they never had an opportunity to carry (Camino, 2000a). Many adults did not employ the most common youthadult partnership strategies put forth in "how-to" manuals such as The Innovation Center's Youth Adult Partnerships: A Training Manual (2003) and Youth on Board's 14 Points: 
Successfully Involving Youth in Decision Making Young and Sazama, (1999) suggesting an unfamiliarity with basic youth-adult partnership concepts or a resistance to using the strategies.

In contrast, staff of programs with strong youth-adult partnerships made mindful, concerted efforts to help youth prepare for and meet challenges even when it would be easier to do the work themselves. This commitment to the partnership was recognized by the youth, "They'll ask us to do a lot of the things that they could be doing, not because they don't want to do it, but because we're responsible enough to do it in a youth group." These staff also pushed the youth as needed. That is, they expected the same level of accountability from the youth as they would from adult partners. They did not shy away from difficult discussions in an effort to avoid being seen as "the bad guy" by the youth.

Three exemplary programs found in our study use the same youth-adult partnership strategies identified as effective in the research literature. The small number of exemplary organizations suggests strong youth-adult partnerships are not easy to implement and that there are many factors that may limit them in the community. The lack of time and resources may prevent full youth involvement even in those organizations that embrace the philosophy. In some cases informing youth and engaging them in problem solving may be the most practical course for an organization. While full youth-adult partnerships may not always be possible, seeking ways to respectfully engage young people will benefit youth, adults and the larger community.

\section{Implications and Conclusion}

Working in partnership is not typically the way that adults and youth interact. Adults usually model their interactions on their experiences as parents or from their days as young students in the classroom. Youth also rely on these models when responding to adults. Both youth and adults would benefit from in-depth training.

Adults and youth need to learn new ways to work together for partnerships to be successful. It is not sufficient simply pretending that youth and adults are "equals." Participants must recognize and value the unique contributions of each group. Youth-adult partnership is not just letting youth "do their thing" while adults watch them fail or perhaps do it themselves at the last moment. For successful results, adults must appropriately coach youth throughout the process.

Mutuality, in which youth and adults teach and learn together and from each other, may be the greatest challenge. Our work in the field indicates that is typically assumed that adults or teachers know everything worth learning and youth and students have little to teach. Minimally, youth are the experts about today's youth culture and how to reach other youth. In brief, adults and youth need to learn together, including how to work in partnerships.

In addition to training, there needs to be concerted efforts within the youth development field to build recognition of the benefits of youth-adult partnerships. There is little reason to believe adults and youth will avail themselves of training opportunities if they "don't know what they don't know." Networking, organizational mentoring, and visits to exemplary programs can all be used to build enthusiasm for this promising methodology. 


\section{References}

Camino, L. (2000a). Youth-adult partnerships: Entering new territory in community work and research. Applied Developmental Science, 4, 11-20.

Camino, L. (2000b). Putting youth-adult partnerships to work for community change: Lessons from volunteers across the county. CYD Journal, 1(4), 7-11.

Fiscus, L. (2003). Youth as equal partners in decision making. The Education Digest, 68(7), 5863.

Gambone, M., Yu, H., Lewis-Charp, H., Sipe, C., \& Lacoe, J. (2004). A Comparative Analysis of Community Youth Development Strategies. Circle Working Paper, University of Maryland.

Goggin, S., Powers, J., \& Spano, S. (2002). Profiles of Youth Engagement \& Voice in New York State: Current Strategies. Cornell, New York: Cornell University.

The Innovation Center for Community and Youth Development, National Network for Youth, Youth Leadership Institute. (2003). Youth adult partnerships: A training manual. Chevy Chase, Md : National 4-H Council.

LeCompte, M.D., \& Schensul, J.J. (1999). Analyzing and interpreting ethnographic data (Vol. 5). Walnut Creek, CA: Alta Mira Press.

Lofquist, W. (1990). A youth opportunity planning process - A systematic approach to involving community groups in strategic planning: Associates for Youth Development.

MacNeil, C. (2005). Youth in Governance Brief. University of California 4-H Youth Development Program.

Males, M.A. (1999). Framing Youth:10 Myths about the Next Generation. Monroe, ME: Common Courage Press.

National 4-H Council. (2005). 4-H: The power of youth. Retrieved September 7, 2006 from: http://www.fourhcouncil.edu/uploadedFiles/News/Summer2005.pdf

Norman, J. (2001). Building effective youth-adult partnerships. Advocates for Youth. Retrieved June 9, 2004 from:

http://www.advocatesforyouth.org/publications/transitions/transitions1401 7.htm.

Patton, M. (2002). Qualitative research and evaluation methods. Thousand Oaks, CA: Sage.

Stoneman, D. (2002). The role of youth programming in the development of civic engagement. Applied Developmental Science, 6(4), 221-226.

Young, K., \& Sazama, J. (1999). 14 points: Successfully involving youth in decision making. Youth on Board. Somerville, MA. 
Zeldin, S., McDaniel, A., Topitzes, D., \& Calvert, H. (2000). Youth in decision making: A study of the impacts of youth on adults and organizations. Chevy Chase, MD: National 4-H Council.

Zeldin, S., McDaniel, A., Topitzes, D., \& Lorens, M.B. (2001). "Bringing young people to the table: Effects on adults and youth organizations," CYD Journal, 2(2) p. 20-27.

(C) Copyright of Journal of Youth Development Bridging Research and Practice. Content may not be copied or emailed to multiple sites or posted to a listserv without copyright holder's express written permission. Contact Editor at: patricia.dawson@oregonstate.edu for details. However, users may print, download or email articles for individual use.

ISSN 2325-4009 (Print); ISSN 2325-4017 (Online) 